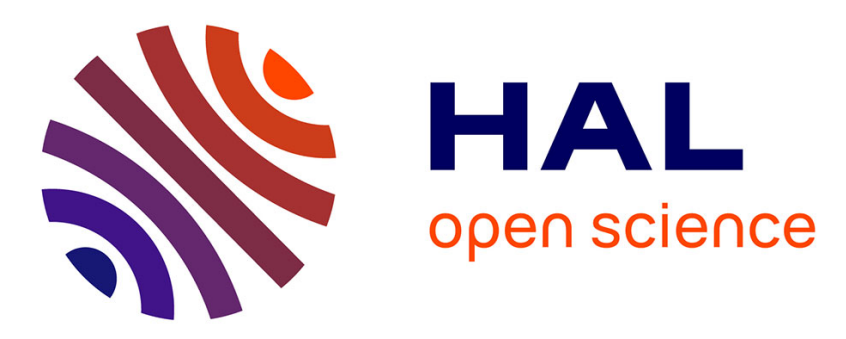

\title{
Effects of accelerated ageing on the adhesive bond between concrete specimens and external CFRP reinforcements
}

Karim Benzarti, Marc Quiertant, Céline Marty, Sylvain Chataigner, Christophe Aubagnac

\section{To cite this version:}

Karim Benzarti, Marc Quiertant, Céline Marty, Sylvain Chataigner, Christophe Aubagnac. Effects of accelerated ageing on the adhesive bond between concrete specimens and external CFRP reinforcements. CICE 2010 - 5th International Conference on FRP Composites in Civil Engineering, Sep 2010, France. pp 385-389. hal-00587909

\section{HAL Id: hal-00587909 \\ https://hal.science/hal-00587909}

Submitted on 21 Apr 2011

HAL is a multi-disciplinary open access archive for the deposit and dissemination of scientific research documents, whether they are published or not. The documents may come from teaching and research institutions in France or abroad, or from public or private research centers.
L'archive ouverte pluridisciplinaire HAL, est destinée au dépôt et à la diffusion de documents scientifiques de niveau recherche, publiés ou non, émanant des établissements d'enseignement et de recherche français ou étrangers, des laboratoires publics ou privés. 


\title{
Effects of accelerated ageing on the adhesive bond between concrete specimens and external CFRP reinforcements
}

\author{
K. Benzarti (benzarti@lcpc.fr), M. Quiertant \& C. Marty \\ Université Paris-Est, Laboratoire Central des Ponts et Chaussées (LCPC), Paris, France
}

S. Chataigner \& C. Aubagnac

Laboratoire Régional des Ponts et Chaussées d'Autun, Autun, France

\begin{abstract}
CFRP strengthened concrete specimens were submitted to accelerated ageing conditions $\left(40^{\circ} \mathrm{C}\right.$ and 95\% R.H.) and the time evolution of the adhesive bond strength was monitored using either pull-off or shear loading tests. In a parallel investigation, effects of hydrothermal ageing on the microstructure of the bulk epoxy adhesives were assessed by means of thermal analyses and tensile tests. From those experiments, it was found that the property evolution of the concrete/FRP bonded interface is primarily dependent on the sensitivity of the polymer to ageing conditions, but also on the type of test used for the mechanical characterizations. These trends were supported by numerical modeling based on finite element analysis.
\end{abstract}

\section{INTRODUCTION}

Applications of Fiber Reinforced Polymer (FRP) composites to the strengthening of civil infrastructures have met a growing popularity in the last decade. If the effectiveness of the technique is now widely recognized (Pendari et al. 2008, Hamelin 2002), many questions remain regarding durability issues (Karbhari et al. 2003). In a more general way, durability aspects are still to be addressed for structural assemblies involving adhesively bonded joints (Cognard 2006).

Design guidelines for FRP strengthened concrete structures usually introduce safety coefficients on the FRP properties, to account for possible deteriorations of both the composite reinforcement itself and the adhesive bond under service conditions (Gangarao et al. 2006, Karbhari et al. 2007). In recent years, extensive researches were undertaken to investigate the environmental ageing behavior of FRP/concrete bonded interfaces (Grace et al. 2005, Yang et al. 2008, Silva et al. 2008, Marouani et al. 2008). Most of these studies showed significant effects of wet environments (direct immersion or exposure to water saturated air) on the long-term performances.

The present study focuses on two FRP reinforcement systems commercially available on the French market, both based on a unidirectional pultruded carbon plate associated to a bi-component/room temperature curing epoxy adhesive.

Concrete specimens were strengthened using these two systems, and the ageing behavior of both the constitutive materials (concrete, epoxies, CFRP plates) and the bonded interfaces were investigated. In this regard, specific ageing conditions were cho- sen, i.e., a temperature of $40^{\circ} \mathrm{C}$ and a relative humidity of at least $95 \%$. Such conditions were intended to accelerate the moisture sorption phenomenon, while keeping the temperature value just below the usual glass transition temperature $(\mathrm{Tg})$ range of ambient cured epoxies used in construction.

The present paper is structured as follows:

- sample preparation and storage conditions are first briefly recalled,

- ageing behaviors of the constitutive materials are then presented, with a special emphasis on epoxy adhesives,

- another section is devoted to the propertyevolutions of the ageing FRP/concrete interfaces, which were assessed using two different characterization methods: the usual pull-off test and a single lap shear test. Apparent evolutions are discussed in the light of the previous results obtained for individual constituents.

- in the final part, a finite element approach is implemented to validate the experimental study.

\section{SAMPLES AND STORAGE CONDITIONS}

\subsection{Samples}

The two FRP systems under study (denoted $S 1$ and $S 2)$ are commercialized by two different manufacturers. $S 1$ and $S 2$ are based on unidirectional pultruded carbon plates of respective widths 100 and $80 \mathrm{~mm}$, respective thicknesses 1.4 and $1.2 \mathrm{~mm}$, and respective Young's moduli of 163 and $165 \mathrm{GPa}$. Specific bi-component epoxy adhesives (denoted Epol 
and Epo2) are respectively used for bonding of systems $S 1$ and $S 2$, according to the product datasheets.

FRP strengthened concrete blocks were specifically designed to enable multiple mechanical characterizations, as shown in Figure 1: concrete compressive strength can be measured on samples cored from the previous specimens, according to EN 12 390-3 standard (2003); adhesive bond characterizations of the concrete/FRP interfaces can be performed either by the pull-off test according to EN 1542 standard (1999), or by a single lap shear test previously detailed in (Chataigner et al. 2009).

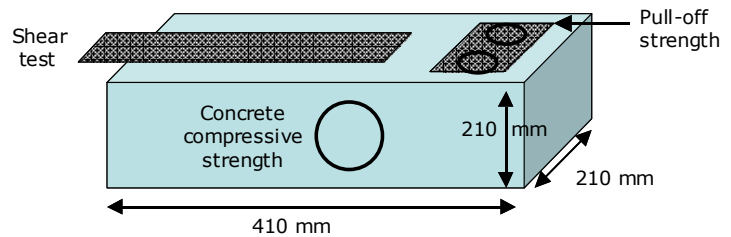

Figure 1. Detail of the CFRP strengthened specimens

Concrete blocks were prepared from CEM II 32.5 cement and silico-calcareous aggregates with a w/c ratio of 0.55 . A maturing period of 28 days was observed before the application of FRP reinforcements.

For each FRP system, a series of 39 reinforced concrete specimens was prepared; this number was intended for 13 test sessions corresponding to different periods of ageing (3 repeated tests per session). Bonding of the FRP systems was achieved by a professional staff according to the guidelines. The bonded length was $200 \mathrm{~mm}$ on each specimen.

Besides, samples of the bulk epoxies were also fabricated, either parallelepiped or dumbbell shaped, in order to study the moisture sorption and perform thermal analyses and tensile tests. Figure 2 shows some pictures of the various samples.

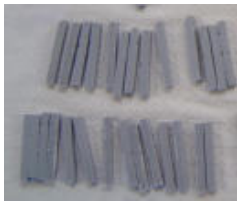

a)

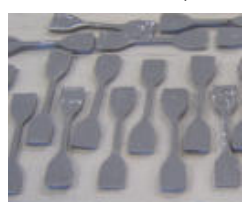

b)

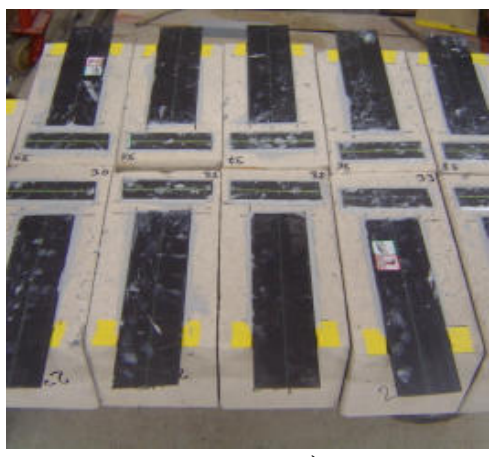

c)
Figure 2. Test samples for bulk epoxies ( $a$ and b) and CFRP strengthened blocks (c)

\subsection{Ageing conditions}

A curing period of 15 days at room temperature was observed before the first test session. Then, samples were placed in a climatic room under ageing conditions (temperature of $40^{\circ} \mathrm{C}$ and relative humidity higher than 95\%), for a total duration up to 20 months (628 days). Series of 3 specimens were peri- odically removed from the chamber in order to be tested. Results of the various characterizations will be presented in the next sections. In all cases, the first test session corresponds to the initial state of the specimens, just before starting the ageing treatment.

\section{AGEING BEHAVIOURS OF CONSTITUTIVE MATERIALS}

\subsection{Evolution of the concrete compressive strength}

Compressive strength of the concrete material was measured on cylindrical samples cored from the CFRP strengthened specimens, at each test session. With ageing time, a slight and progressive increase was observed in the compressive strength values (from $35 \mathrm{MPa}$ in the initial state to about $43 \mathrm{MPa}$ after 20 months). Such a trend was expected due to the continuation of the hydration process in the warm and wet ageing environment.

\subsection{Evolution of the CFRP plate properties}

Tensile tests performed on CFRP plates from systems $S 1$ and $S 2$ did not reveal any significant evolution of the material stiffness over ageing time. Young's moduli remained unchanged with values around 160GPa.

\subsection{Ageing behaviors of the bulk epoxies}

Mass uptakes of the two ambient temperature cured epoxies Epo1 and Epo2 were first monitored as a function of ageing time (Figure 3 a). Fickian behaviors were observed for the two systems, but with a much higher saturation level for Epol ( 2-2.5\%) than for system Epo2 ( 0.8\%).
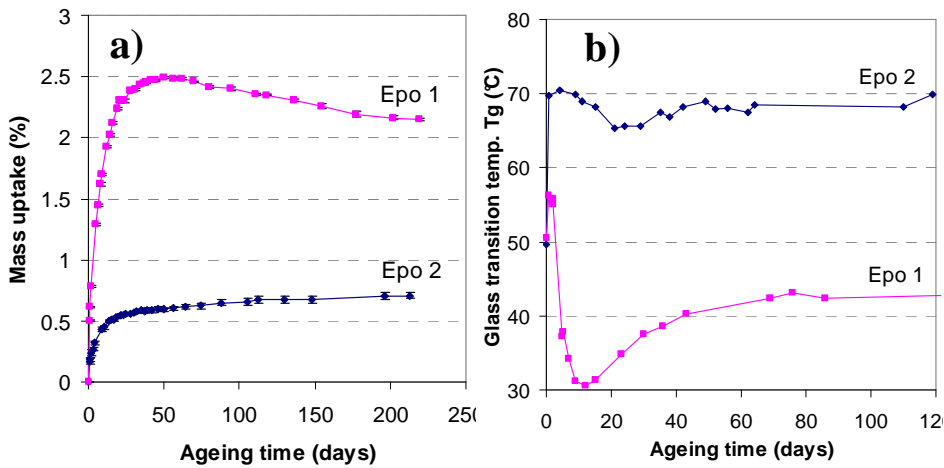

Figure 3. Mass uptakes (a) and evolution of the glass transition temperature (b) versus ageing time for bulk adhesives Epol and Epo2.

Changes in the glass transition temperature (Tg) induced by ageing were determined using a modulated differential scanning calorimetry (MDSC). Observed variations (Figure $3 \mathrm{~b}$ ) were ascribed to the competition between two antagonistic phenomena: the postcuring of the adhesive leading to an increase in $\mathrm{Tg}$, and the plasticization effect which produces the opposite trend. The two systems exhibited very different behaviors: a large drop of $\mathrm{Tg}$ was observed for 
Epol (down to $30^{\circ} \mathrm{C}$ ), which indicates an extensive plasticization due to moisture sorption; differently, Epo2 showed much more limited plasticization and kept its $\mathrm{Tg}$ value higher than $60^{\circ} \mathrm{C}$.

Tensile tests were also performed and the stressstrain curves obtained after various periods of ageing are plotted in Figure 4. Tensile characteristics of the two ageing epoxies both evolved from an elastic behavior toward an elasto-plastic behavior, with a decrease in strength and an improved ductility. However, ductilization was much more pronounced for Epo1 than for Epo2 in line with the extensive plasticization revealed by sorption and DSC experiments.
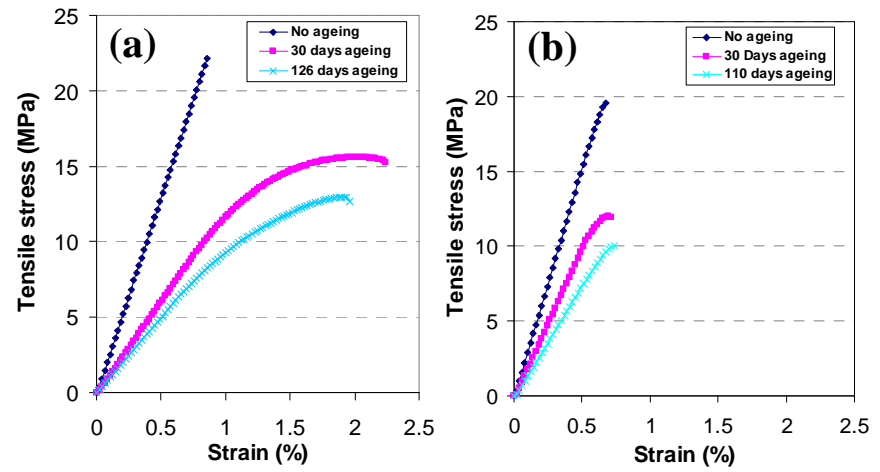

Figure 4. Tensile stress-strain curves for bulk epoxies Epol (a) and Epo2 (b), after various ageing periods.

\section{AGEING BEHAVIOURS OF CONCRETE / FRP INTERFACES}

This part investigates the property evolutions of the adhesive bond during ageing as determined using the pull-off and single-lap shear tests.

\subsection{Pull-off characterizations}

Figures 5 and 6 depict respectively the evolutions of the pull-off strengths and failure modes for ageing CFRP strengthened specimens of type $S 1$ and $S 2$.

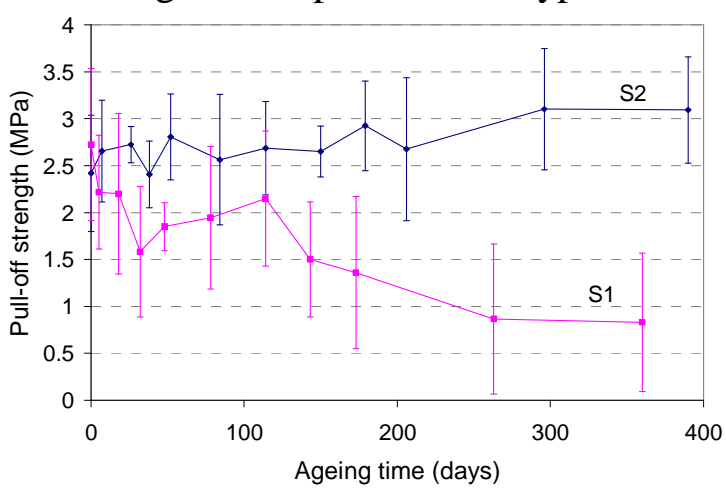

Figure 5. Evolution of the pull-off strengths versus ageing time for specimens strengthened by CFRP systems $S 1$ and $S 2$.

Systems $S 1$ and $S 2$ exhibited very different ageing behaviors: a large decrease in the pull-off strength and an evolution of the failure mode from a substrate failure towards a cohesive failure within the glue were observed for system $S 1$, whereas no significant evolution was observed for system $S 2$. This point will be discussed further in the next section.

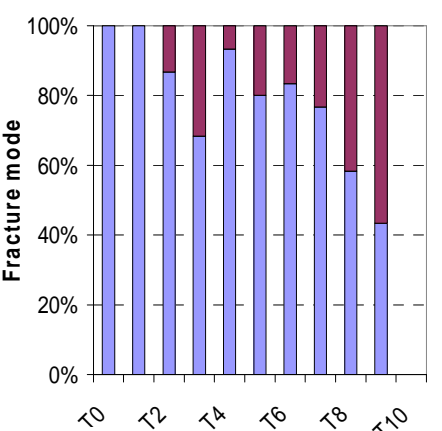

a) Test sessions

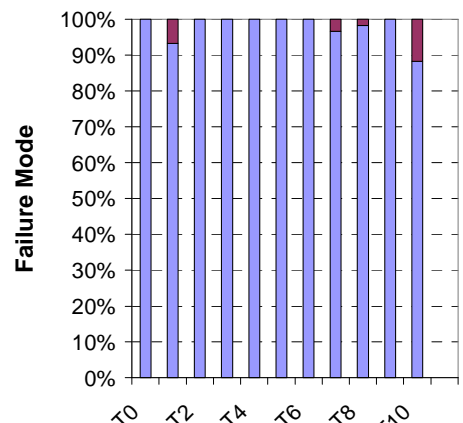

$\square$ Glue failure
$\square$ Concrete failure Test sessions b)

Figure 6. Evolution of the failure mode for specimens of type $S 1$ (a) and $S 2$ (b) after pull-off tests.

\subsection{Single-lap shear tests}

Figures 7 and 8 display respectively the evolutions of the maximum shear loads and failure modes for ageing specimens of type $S 1$ and $S 2$.

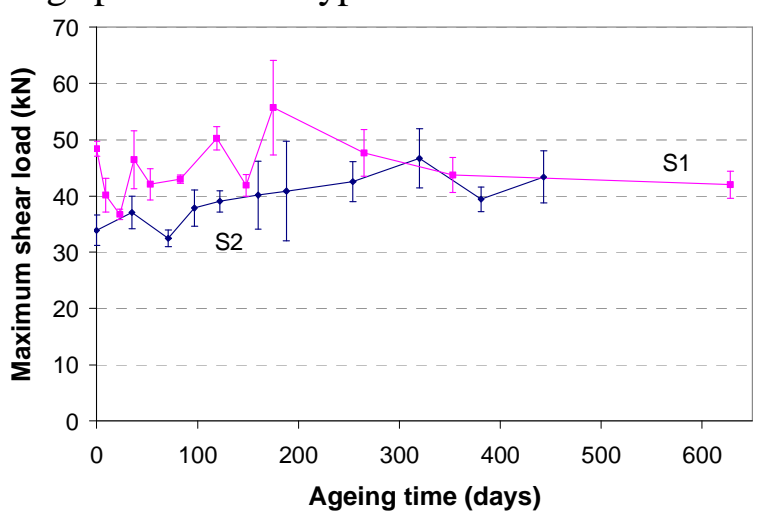

Figure 7. Evolution of the maximum shear load versus ageing time for specimens strengthened by CFRP systems $S 1$ and $S 2$.
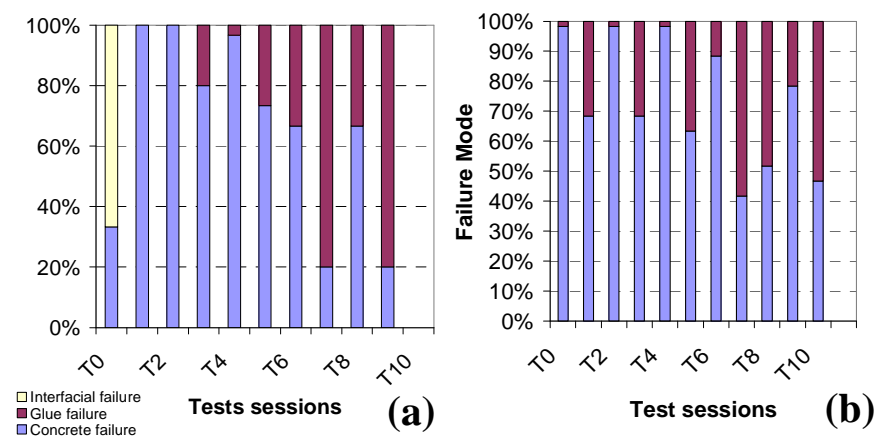

Figure 8. Evolution of the failure mode for specimens of type $S 1$ (a) and $S 2$ (b) after single lap shear tests.

Failure mode of the shear tested interfaces evolved for both systems $S 1$ and $S 2$, from a concrete failure toward a failure within the glue layer. This is consistent with a deterioration of the glue properties after ageing, as shown previously on samples of the bulk epoxies. Surprisingly, no significant evolution of the maximum shear load was obtained for the two systems, despite the change in the fracture mode. Complementary data provided by a strain gage instrumentation revealed that the shear load transfer along the joint is affected by ageing (increase of the transfer length due to the plasticization of the glue), which might explain the unchanged shear capacity. 
Another point is the divergence between the pulloff and shear test results. The pull-off method clearly showed a deterioration of the adhesive bond characteristics for system $S 1$ (based on glue EPO1, which undergoes a large plasticization during ageing), but not for system $S 2$. Differently, the shear test revealed a marked evolution of the failure mode for the 2 systems, suggesting bond deterioration in both cases.

It is believed that the pull-off test is less sensitive than the shear test to ageing induced changes in the adhesive bond properties.

\section{FINITE ELEMENT MODELING}

Finite element approaches were then implemented using CESAR-LCPC software (CESAR 2010), in order to confirm some of the experimental trends.

\subsection{Modeling of the pull-off test}

In a first step, a modeling of the pull-off configuration (not detailed here) showed that the test is not based on a pure tensile loading of the bonded joint, and revealed local stress concentrations within the substrate due to the partial coring of concrete around the test zone. This finding supports that the pull-off test might exhibit a low sensitivity to actual changes in the bond properties.

\subsection{Modeling of the single lap shear configuration}

A modeling was finally proposed in order to simulate the single lap shear test in the case of a non aged CFRP reinforced specimen (considering a glue layer with a pure elastic behavior) or an aged specimen (with an elasto-plastic behavior of the glue similar to that of EPO1 after ageing).

Simulations confirmed the increase in the load transfer length for the aged specimen due to the plastic deformation of the polymer adhesive, and pointed out a better diffusion of the shear stress within the aged specimen, as shown in Figure 9. These findings are consistent with experimental observations.

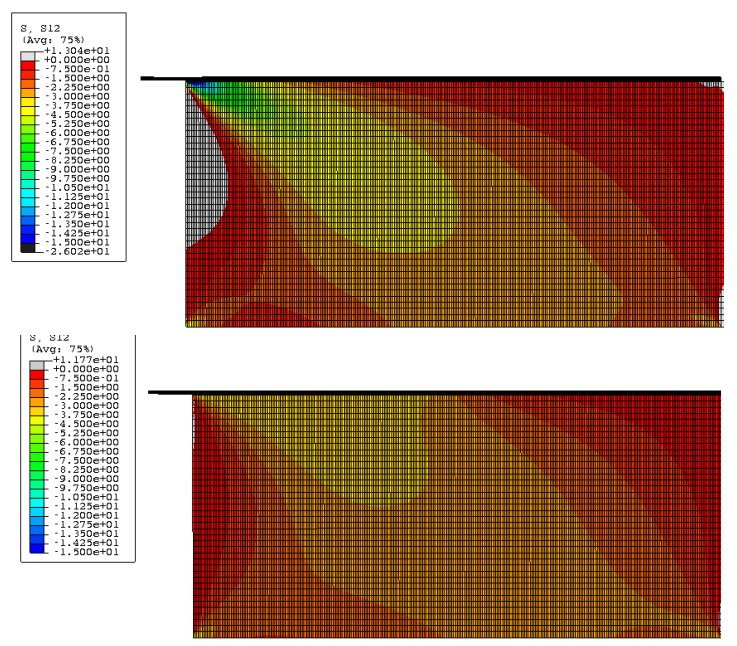

Figure 9. Representation of the stress field within a shear tested CFRP reinforced specimen. Results in the initial state (a) and after ageing (b).

\section{CONCLUSION}

In this work, ageing behaviors of two FRP strengthening systems based on pultruded carbon plates have been investigated. Ageing conditions consisted in exposing specimens at $40^{\circ} \mathrm{C}$ and $95 \% \mathrm{RH}$.

Investigations on the bulk materials revealed that both adherents (concrete, carbon plates) did not notably evolve during ageing, whereas epoxy adhesives underwent more or less severe plasticization effects depending on their formulation.

Adhesive bond characterizations relied on pull-off and single lap shear tests. It was found that results of the two methods were not always correlated. The shear test revealed a clear evolution of failure modes for the 2 FRP plate systems. The weakest part of the assembly, initially assigned to the concrete substrate, became progressively the polymer joint. A strain gage equipment made it possible to detect a major change in the load transfer mechanism along the joint (increase in the transfer length). These findings were finally supported by finite element simulations.

\section{REFERENCES}

CESAR-LCPC website. 2010. http://www.cesar-lcpc.com

Chataigner, S. Caron, J.F. Benzarti, K. Quiertant, M. \& Aubagnac, C. 2009. Characterization of composite to concrete bonded interface: Description of the single lap shear test. Eur. J. Environ. Civ. Eng. 13 (9):1073-1082.

Cognard, J. 2006. Some recent progress in adhesion technology and science. Comptes-Rendus de Chimie 9: 13-24.

EN 1542. 1999. Products and systems for the protection and repair of concrete structures. Test methods. Measurement of bond strength by pull-off.

Gangarao, H. Taly, N. \& Vijay P.V. 2006. Reinforced concrete design with FRP composites. Taylor \& Francis, CRC Press.

Grace, N.F \& Singh, S.B. 2005. Durability Evaluation of Carbon Fiber-Reinforced Polymer Strengthened Concrete Beams: Experimental Study and Design, ACI Structural Journal 102(1): 40-51.

Hamelin, P. 2002. Renforcement des ouvrages d'art par matériaux composites. Tech. de l'Ingénieur AM5615: 1-10

Karbhari, V.M. \& Abanilla, M.A. 2007. Design factors, reliability, and durability prediction of wet layup carbon/epoxy in external strengthening. Composites: Part B 38: 10-23.

Karbhari, V.M. Chin, J.W. and al. 2003. Durability gap analysis for fiber-reinforced polymer composites in civil infrastructure. J. of Composites for Construction 7(3): 238-247

Marouani, S. Curtil, L. \& Hamelin, P. 2008. Composites realized by hand lay-up process in civil engineering environment: initial properties and durability. Materials and Structures 41(5): 831-851.

NF EN 12390-3. 2003. Testing hardened concrete. Part 3: Compressive strength of test specimens.

Pendari, S.S. Kant, T. \& Desai, Y.M. 2008. Application of polymer composites in civil construction: A general review. Composite structures 84: 114-124.

Silva, M.A.G. \& Biscaia, H. 2008. Degradation of bond between FRP and RC beams. Compos. Struct. 85: 164-174.

Yang, Q.A. Xian, G.J. \& Karbhari, V.M. 2008. Hygrothermal ageing of an epoxy adhesive used in FRP strengthening of concrete. J. of Applied Polymer Science 107(4): 2607-2617. 